\title{
Clinical Manifestations of Overactive Bladder With Migraine as a Comorbidity: A Prospective Cross-Sectional Study
}

\author{
Aykut Baser ${ }^{1}$, Sinan Eliaçık ${ }^{2}$, Mehmet Murat Baykam ${ }^{1}$, Funda Uysal Tan² \\ ${ }^{1}$ Department of Urology, Hitit University School of Medicine, Corum, Turkey \\ 2Department of Neurology, Hitit University School of Medicine, Corum, Turkey
}

\begin{abstract}
Purpose: The aim of this study was to investigate the clinical manifestations of overactive bladder (OAB) with migraine as a comorbidity and to shed light on possible new treatment strategies.

Methods: This study included patients aged 18 years and older who were admitted to urology and neurology outpatient clinics between March 1, 2019 and March 1, 2020 for OAB and migraine. The study questionnaire contained 3 sections: (1) questions on demographic characteristics, (2) a migraine ID test, and (3) the Overactive Bladder Inquiry Form - V8 (OAB-V8) form.

Results: A total of 265 patients participated in the study. The average age of the participants was $39.75 \pm 11.93$ years. The patients were divided into 3 groups according to the coexistence of $\mathrm{OAB}$ with migraine: group 1, $\mathrm{OAB}(+) /$ migraine(+); group 2, $\mathrm{OAB}(+) /$ migraine(-); and group $3, \mathrm{OAB}(-) /$ migraine $(+)$. The mean $\mathrm{OAB}-\mathrm{V} 8$ score was $22.82 \pm 8.15$ in group 1 and $25.64 \pm 7.49$ in group 2 . The mean $\mathrm{OAB}-\mathrm{V} 8$ score of $\mathrm{OAB}$ patients with migraine as a comorbidity was statistically significantly lower than that of $\mathrm{OAB}$ patients without migraine $(\mathrm{P}=0.015)$. The median visual analogue scale (VAS) score was 7.11 (range, $2-10$ ) in group 1 and 5.95 (range, 2-10) in group 3. This finding indicates that in patients with migraine, having OAB was associated with significantly higher VAS scores $(\mathrm{P}<0.001)$.

Conclusions: $\mathrm{OAB}$ and migraine may be comorbid conditions coexisting in a single patient. This comorbidity may lead to a lower perception of $\mathrm{OAB}$ symptoms in $\mathrm{OAB}$ patients or, conversely, to a higher perception of migraine pain. Further studies are needed to elucidate how treatments for each of these diseases can affect the other disease.
\end{abstract}

Keywords: Urinary bladder, Overactive; Migraine disorders; Urinary incontinence; Nocturia

- Research Ethics: This study was approved by the local human subjects research ethics committee and conducted in accordance with the Strengthening the Reporting of Observational studies in Epidemiology (STROBE) guidelines for reporting observational studies (www. strobestatement.org). Pamukkale University noninvasive clinical research ethics committee approval number is 60116787-020/3659. Written informed consent was obtained from patients.

- Conflict of Interest: No potential conflict of interest relevant to this article was reported.

\section{INTRODUCTION}

Overactive bladder $(\mathrm{OAB})$ is characterized by symptoms of urgency, with or without urgency incontinence, usually with increased daytime frequency and nocturia (increased night-time urination) [1]. Its prevalence in the community is between $7 \%$ and $32.6 \%$ [1-4]. OAB is a clinical condition based on symptoms, rather than a disease. It is known that nonurological symptoms are more common in $\mathrm{OAB}$ patients, apart from the lower urinary tract symptoms (LUTS) described above, than in

Corresponding author: Aykut Başer (iD https://orcid.org/0000-0003-0457-512X Department of Urology, Hitit University School of Medicine, Corum, Turkey E-mail: aqut85@windowslive.com

Submitted: May 28, 2020 / Accepted after revision: July 5, 2020

This is an Open Access article distributed under the terms of the Creative Commons Attribution Non-Commercial License (https://creativecommons.org/licenses/by-nc/4.0/) which permits unrestricted non-commercial use, distribution, and reproduction in any medium, provided the original work is properly cited. 
the general population. In previous studies, it was reported that fibromyalgia, heart failure, diabetes, hypertension, arthritis, and neurological diseases coexisted more frequently in patients with $\mathrm{OAB}$ than in the general population [5-8]. Furthermore, it is remarkable that $\mathrm{OAB}$ also frequently coexists with different types of headache, as diagnosed with clinical symptoms and various questionnaires. Lai et al. [9] used the Polysymptomatic Polysyndromic Questionnaire and observed more frequent headaches in OAB patients. Similarly, Ramos et al. [10] reported a higher prevalence of $\mathrm{OAB}$ in chronic migraine $(\mathrm{CM}) \mathrm{pa}$ tients than in the general population. Although there is evidence that $\mathrm{OAB}$ and migraine, which are pathophysiologically similar, may coexist, no publication in the literature has yet addressed their clinical manifestations. Our aim in this study was to investigate the clinical manifestations of $\mathrm{OAB}$ with migraine as a comorbidity and to shed light on new developments for treatment in the future.

\section{MATERIALS AND METHODS}

This study is a cross-sectional prospective study. This study was approved by the local human subjects research ethics committee and conducted in accordance with the Strengthening the Reporting of Observational studies in Epidemiology (STROBE) guidelines for reporting observational studies (www.strobestatement.org).

\section{Study Group and Inclusion and Exclusion Criteria}

This study included patients 18 years of age and older admitted to urology and neurology outpatient clinics between March 1, 2019 and March 1, 2020 who were evaluated by 2 specialist physicians (1 urologist, 1 neurologist) for $\mathrm{OAB}$ and migraine. During the interview, patients were informed about the study and provided written informed consent. Patients diagnosed with $\mathrm{OAB}$ in the urology outpatient clinic were evaluated for migraine in the neurology department and, conversely, patients diagnosed with migraine in the neurology outpatient clinic were also evaluated for $\mathrm{OAB}$ in the urology department. The diagnosis of migraine was made with the migraine ID test and clinical evaluation by the physician.

The exclusion criteria were:

- Having a urinary tract infection

- Having neurogenic bladder or a condition that can cause neurogenic bladder (such as spinal cord injury or peripheral nerve disease)

- History/diagnosis of interstitial cystitis
- History of bladder or prostate cancer, bladder stone, or pelvic mass

- Voiding LUTS with a maximal flow rate $<15 \mathrm{~mL} / \mathrm{sec}$ in uroflowmetry and/or an intermittent voiding pattern

- Having symptomatic or severe pelvic organ prolapse

- Vaginal cancer

- Having concomitant diseases that cause fluid shifts, such as congestive heart failure, cirrhosis, or pulmonary edema

- Use of diuretics and similar medicines

- Excessive fluid consumption (assessed by a voiding diary of at least 3 days)

The selection of patients admitted to the urology and neurology outpatient clinics is presented in Fig. 1.

\section{Questionnaires and Definitions}

The study questionnaire was prepared by the research team, and was filled out by the doctor who informed the patient about the study. It contained 3 sections: (1) a demographic descriptive section, including age, sex, height, weight, and body mass index (BMI) of the participants; (2) the migraine ID test for the diagnosis of migraine in accordance with the International Headache Society (IHS) [11] definition of CM, which was any headache occurring $\geq 15$ days per month for at least 3 months with migraine features on $\geq 8$ days every month, headache without excessive drug use and nonattributable to another reason, and a visual pain scale score between 0 and 10 points for qualitative evaluation of migraine pain; and (3) the Overactive Bladder Inquiry Form - V8 (OAB-V8) consisting of 8 questions (scored with a range of $0-5$ points), which was developed in 2006 by Acquadro et al. [12] for the screening and awareness of OAB. The validity and reliability of the Turkish version of the OAB-V8 were confirmed by Tarcan et al. [13], according to the 2002 International Continence Society (ICS) definition of OAB [1].

\section{Statistical Analysis}

To evaluate the findings obtained in this study, SPSS version 22.0 (IBM Co., Armonk, NY, USA) was used. Conformity of the parameters to the normal distribution was evaluated by the Kolmogorov-Smirnov and Shapiro-Wilk test. Descriptive statistical values were computed (mean, standard deviation, frequency, median, range). The Mann-Whitney U-test was used for comparisons between 2 groups for parameters without a normal distribution, and Student $\mathrm{t}$-test was used for parameters with a normal distribution. The Kruskal-Wallis test was used to 


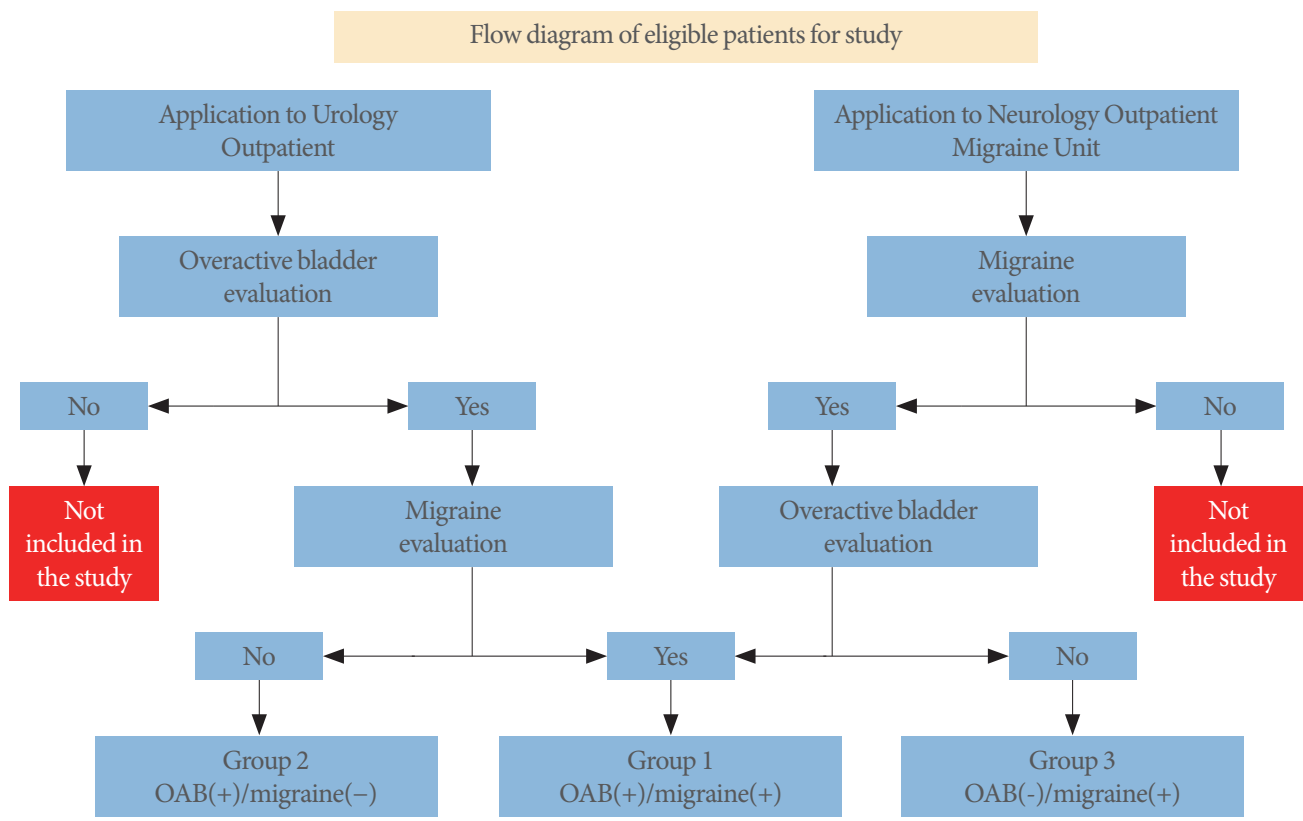

Fig. 1. Flow diagram of eligible patients for study. OAB, overactive bladder.

compare differences in age and BMI among the 3 groups. The results were presented with a confidence interval of $95 \%$. A Pvalue $<0.05$ was considered to indicate statistical significance.

\section{RESULTS}

\section{General Population}

A total of 265 patients (143 patients from the urology outpatient clinic and 122 patients from the neurology outpatient clinic) participated in the study. The patients were divided into 3 groups according to the presence of $\mathrm{OAB}$ and migraine: group $1, \mathrm{OAB}(+)$ /migraine(+); group 2, $\mathrm{OAB}(+) /$ migraine(-); group 3, $\mathrm{OAB}(-) /$ migraine $(+)$ (Table 1$)$. Migraine was found to be present as a comorbidity in $39.9 \%$ of $\mathrm{OAB}$ patients, while $\mathrm{OAB}$ was present as a comorbidity in $37.7 \%$ of migraine patients. The average age of the participants in the study was $39.75 \pm 11.93$ years (range, 18-65 years), and the mean BMI was $26.89 \pm 5.64 \mathrm{~kg} / \mathrm{m}^{2}$ (range, $16.05-46.99 \mathrm{~kg} / \mathrm{m}^{2}$ ). At least 1 comorbid disease was found in $27.92 \%$ of the patients. The demographic characteristics of the patients are presented in Table 2.

\section{Evaluation of Symptoms}

The OAB-V8 scores of OAB patients with migraine as a comorbidity (group 1) and without migraine as a comorbidity (group 2) were analyzed. The OAB-V8 score was $22.82 \pm 8.15$ in group 1 and $25.64 \pm 7.49$ in group 2 , corresponding to a statistically
Table 1. Classification of patient groups according to their diagnosis

\begin{tabular}{lcccc}
\hline $\begin{array}{c}\text { Clinic where the } \\
\text { patient presented }\end{array}$ & Group 1 & Group 2 & Group 3 & Total \\
\hline Urology clinic & $57(39.9)$ & $86(60.1)$ & $0(0)$ & $143(100)$ \\
Neurology clinic & $46(37.7)$ & $0(0)$ & $76(62.3)$ & $122(100)$ \\
Total & $103(38.9)$ & $86(32.5)$ & $76(28.7)$ & $265(100)$ \\
\hline
\end{tabular}

Values are presented as number (\%).

$\mathrm{OAB}$, overactive bladder; group $1, \mathrm{OAB}(+) /$ migraine(+); group 2, $\mathrm{OAB}(+)$ /migraine(-); group $3, \mathrm{OAB}(-)$ /migraine(+).

significantly lower mean $\mathrm{OAB}-\mathrm{V} 8$ score in $\mathrm{OAB}$ patients with migraine as a comorbidity $(\mathrm{t}[0.547]=-2.458, \mathrm{P}=0.015)$. We further analyzed the OAB-V8 scores according to sex. In women, the mean OAB-V8 scores in group 1 and group 2 were $21.93 \pm$ 7.87 and $25.83 \pm 7.48$, respectively $(\mathrm{t}[143]=-3.019, \mathrm{P}=0.003)$, while in men, they were $26.29 \pm 8.50$ and $25.13 \pm 7.68$, respectively $(\mathrm{t}[42]=0.473, \mathrm{P}=0.638)$. Women had significantly lower $\mathrm{OAB}-\mathrm{V} 8$ scores than men in group $1(\mathrm{t}[101]=-2.227, \mathrm{P}=0.028)$, while there was no such difference in group 2.

Visual analogue scale (VAS) scores were used to evaluate the migraine pain scores of migraine patients with $\mathrm{OAB}$ as a comorbidity (group 1) and without $\mathrm{OAB}$ as a comorbidity (group 3). The median VAS score was 7.11 (range, 2-10) in group 1 and $5.95(2-10)$ in group 3. In patients with migraine, having $\mathrm{OAB}$ was associated with significantly higher VAS scores $(\mathrm{U}=$ 
Table 2. Demographic characteristics of the patients

\begin{tabular}{|c|c|c|c|c|}
\hline Characteristic & Group 1 & Group 2 & Group 3 & P-value \\
\hline Age (yr) & $40.20 \pm 10.39$ & $44.50 \pm 13.74$ & $33.76 \pm 8.80$ & $<0.001^{\star}$ \\
\hline Body mass index $\left(\mathrm{kg} / \mathrm{m}^{2}\right)$ & $27.04 \pm 5,60$ & $29.14 \pm 6.17$ & $24.13 \pm 3.58$ & $<0.001^{\star}$ \\
\hline Sex & & & & $<0.001^{\star}$ \\
\hline Female & $82(79.6)$ & $63(73.3)$ & $71(93.4)$ & \\
\hline Male & $21(20.4)$ & $23(26.7)$ & $5(6.6)$ & \\
\hline Diabetes & & & & $0.019^{*}$ \\
\hline Yes & $7(6.8)$ & $9(10.5)$ & $0(0)$ & \\
\hline No & $99(93.2)$ & $77(89.5)$ & $76(100)$ & \\
\hline Hypertension & & & & $0.002^{*}$ \\
\hline Yes & $11(10.7)$ & $14(16.3)$ & $0(0)$ & \\
\hline No & $92(89.3)$ & $72(83.7)$ & $76(100)$ & \\
\hline Asthma & & & & 0.179 \\
\hline Yes & $3(2.9)$ & $4(4.7)$ & $0(0)$ & \\
\hline No & $100(97.1)$ & $82(95,3)$ & $76(100)$ & \\
\hline Others $^{\text {a) }}$ & & & & $0.039^{*}$ \\
\hline Yes & $12(11.7)$ & $12(14)$ & $2(2.6)$ & \\
\hline No & $91(88.3)$ & $74(86)$ & $74(97.4)$ & \\
\hline
\end{tabular}

Values are presented as mean \pm standard deviation or number (\%).

$\mathrm{OAB}$, overactive bladder; group $1, \mathrm{OAB}(+)$ /migraine $(+)$; group $2, \mathrm{OAB}(+)$ /migraine(-); group 3, $\mathrm{OAB}(-) /$ migraine $(+)$.

${ }^{\text {a) }}$ Coronary artery disease, gastrointestinal system disease, etc. ${ }^{\star} \mathrm{P}<0.05$, statistically significant difference.

\section{5, $\mathrm{P}<0.001)$.}

When the responses of groups 1 and 2 to the OAB-V8 were examined, the groups were found to be similar in their responses to the questions regarding accidental loss of small amounts of urine, an uncontrollable urge to urinate, and urine loss associated with a strong desire to urinate. A statistically significant difference was found in favor of group 2 (Table 3). When we analyzed the results according to sex, we observed that this difference mainly stemmed from female patients. In men, only urine loss associated with a strong desire to urinate showed a significantly higher score in group 1 than in group 2 . The responses of groups 1 and 2 to the OAB-V8 questions are summarized in Fig. 2.

\section{DISCUSSION}

This study is the first prospective cross-sectional study to investigate the symptoms and clinical findings of migraine as a comorbidity in patients with $\mathrm{OAB}$, in accordance with the definitions of the ICS and IHS. In our study, we demonstrated that $37.7 \%$ of patients with a diagnosis of migraine had $\mathrm{OAB}$ as a comorbidity, a proportion that is slightly higher than has been reported in the general population $(7 \%-32.6 \%)$ [1-4]. The prevalence of $\mathrm{OAB}$ in migraine patients in our study is similar to the prevalence of OAB (36.4\%) in the study of Ramos et al. [10] which included 231 patients with migraine. In our study, we also found that the presence of migraine in $\mathrm{OAB}$ patients was $39.9 \%$. This ratio is higher than the previously reported prevalence of migraine (5\%-21.8\%) [14-17]. The clustering of both conditions as comorbidities was disproportionately frequently observed in our study, in accordance with the literature $[10,18]$. Coyne et al. [7] investigated comorbid conditions in patients with and without LUTS, and they reported that LUTS could be associated with a higher number of comorbid conditions that share common pathophysiological pathways.

Many causes such as decreased suprapontine inhibition, damage to axonal pathways in the spinal cord, peripheral nerve injury, loss of peripheral inhibition, increased effect of stimulating neurotransmitters in voiding reflex pathways, and increased afferent stimuli from the lower urinary system play a role in the pathophysiology of OAB. Multiple causes are also involved in the pathophysiology of migraine. The following theories have 


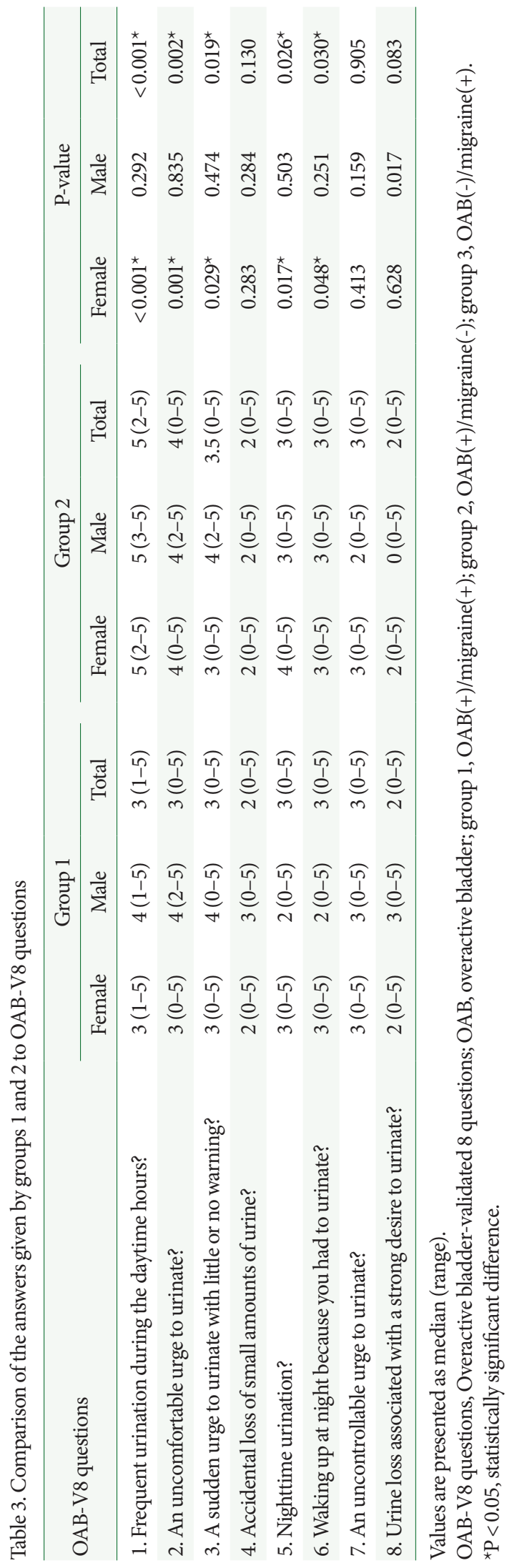

been proposed for the pathophysiology of migraine: (1) the neuronal theory, according to which a sterile inflammatory response occurs due to serotonin receptor activation, and (2) the neurovascular theory, which postulates that attacks occur due to vasodilatation, which is a consequence of protein extravasation with the release of antidromic neuropeptides (calcitonin gene-related peptide [CGRP], substance P, neurokinin A) to the perivascular area and increased blood flow - in other words, neurogenic inflammation combined with nitric oxide and vasoactive intestinal polypeptide release. Therefore, the pathogenesis of migraine involves many cortical and subcortical structures in the brain parenchyma, as well as pain-sensitive structures, meninges, and blood vessels. The etiologies of both $\mathrm{OAB}$ and migraine are multifactorial. In the literature, some explanations have been proposed for the frequent co-occurrence of $\mathrm{OAB}$ and migraine. Ramos et al. [10] suggested that recurrent attacks of pain in migraine patients may sensitize central pain pathways and that increased abnormal sensory activity may also play a role in the pathophysiology of OAB. CGRP plays a role in both $\mathrm{OAB}$ and migraine. CGRP causes vasodilatation and neurogenic inflammation in leptomeningeal and extracranial vessels in migraine patients. Fowler et al. [19] reported that the density of suburothelial nerve fibers, which are immunoreactive for CGRP, increased in OAB patients. It was demonstrated that onabotulinumtoxin $A$, which is used in the treatment of both diseases, inhibited the uptake of CGRP in the bladder in experimental animals and also attenuated the increased CGRP levels in migraine patients [20,21]. Moreover, central brain structures such as cortical, hypothalamic, and periaqueductal gray nuclei are also jointly involved in the development of $\mathrm{OAB}$ and migraine [19]. Ramos et al. [10] stated that migraine and $\mathrm{OAB}$ are comorbid conditions and can share similar pathophysiological mechanisms. In the same study, they suggested that migraine patients should be asked whether they experience $\mathrm{OAB}$ symptoms, and vice versa, $\mathrm{OAB}$ patients should be questioned about migraine in clinical practice, and they pointed out the need for further epidemiological studies [10].

In our study, among the patients diagnosed with $\mathrm{OAB}$, the $\mathrm{OAB}-\mathrm{V} 8$ scores of the patients in group 1 (migraine[+]) were lower than those of patients in group 2 (migraine[-]). Moreover, in a subgroup analysis according to sex, we found that this difference was significant in women only. The fact that our study is the first publication in the literature to investigate such a relationship makes it difficult to interpret this situation. As we know from micturition control and lower urinary tract physiol- 

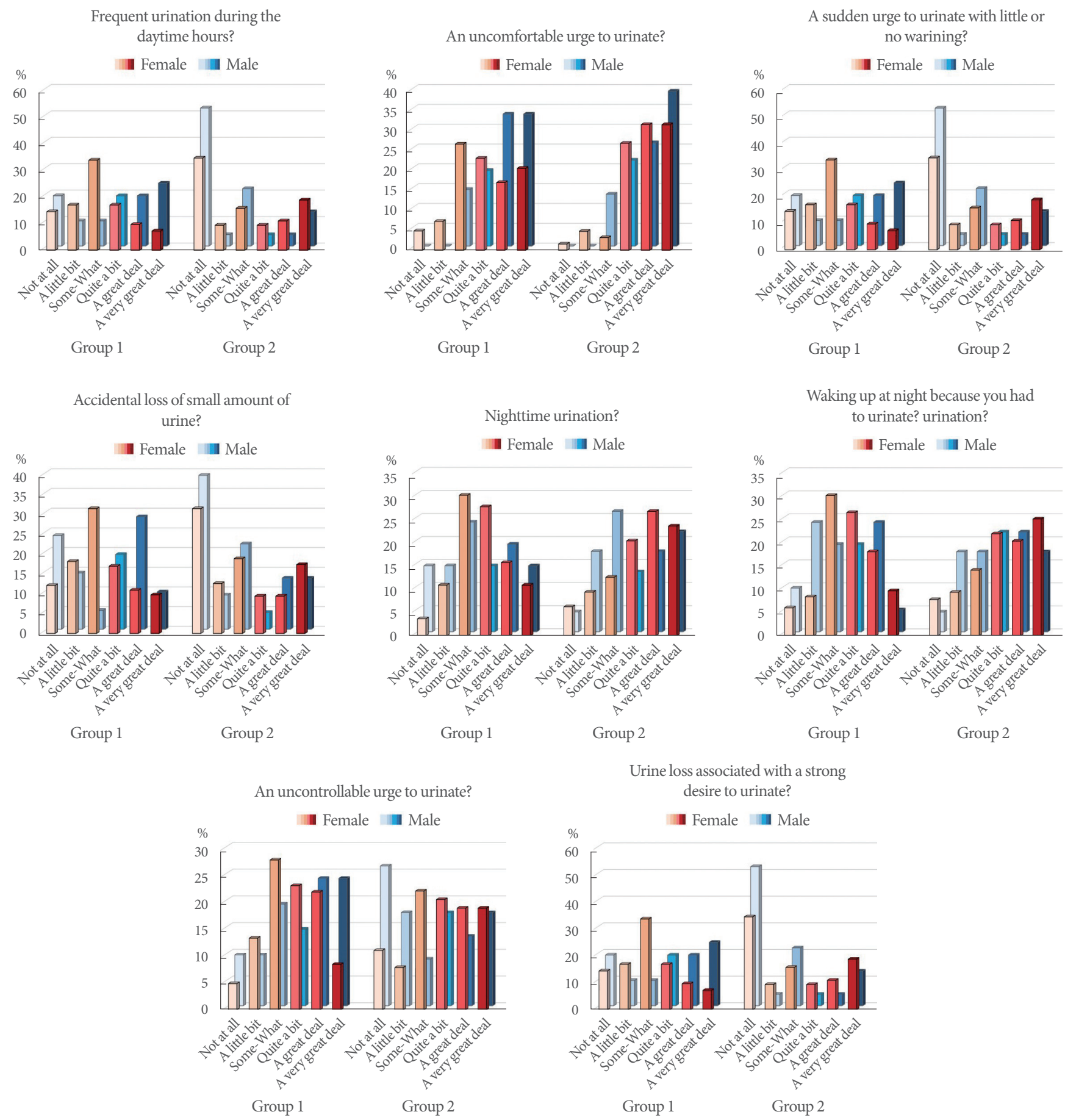

Fig. 2. Graphical representation of the answers to the $\mathrm{OAB}-\mathrm{V} 8$ questions of groups 1 and 2. OAB-V8, Overactive Bladder Inquiry Form - V8; $\mathrm{OAB}$, overactive bladder; group $1, \mathrm{OAB}(+) /$ migraine(+); group 2, $\mathrm{OAB}(+) /$ migraine $(-)$.

ogy, sensations are transferred from the bladder to the cortical area after preliminary evaluation in the insula and thalamus. Therefore, excessive stimulation of the cortex due to migraine suppresses stimuli from the bladder, or OAB symptoms may become of secondary importance due to migraine pain. When patients' responses to the questions in the $\mathrm{OAB}-\mathrm{V} 8$ were examined, it was revealed that group $1(\mathrm{OAB}[+] /$ migraine $[+])$ urinated less frequently, had bothersome urinary urgency less fre- 
quently, had unexpected urinary urgency less frequently, urinated less frequently at night, and less frequently woke up to urinate at night. This situation may be related to the aspects of pathophysiology described above and further studies are needed.

Our study was not without limitations. Because of its multidisciplinary protocol, and the fact that it included all suitable patients according to the inclusion criteria within a limited timeframe, the patient group was not homogeneous and there were differences between groups in the mean values of several parameters (age, sex, etc.). The main reason for this was the patients with isolated migraine (group 3). Since these patients were younger, they had fewer comorbidities. Further studies with a higher number of patients and more homogeneous groups may overcome any doubts regarding this issue.

In conclusion, since $\mathrm{OAB}$ and migraine are common conditions in the general population, they may be comorbid conditions existing in a single patient. This comorbidity may lead to lower perceptions of OAB symptoms or, conversely, higher perceptions of migraine pain. In this study, it was demonstrated that the presence of migraine led to a decrease in OAB symptom scores in $\mathrm{OAB}$ patients, which was more prominent in women, and that the presence of $\mathrm{OAB}$ led to an increase in pain scores in migraine patients. Further studies are needed to confirm these findings and to elucidate how treatments for each of these diseases can affect the other disease.

\section{REFERENCES}

1. Abrams P, Cardozo L, Fall M, Griffiths D, Rosier P, Ulmsten U, et al. The standardisation of terminology of lower urinary tract function: report from the Standardisation Sub-committee of the International Continence Society. Neurourol Urodyn 2002;21:167-78.

2. Irwin DE, Kopp ZS, Agatep B, Milsom I, Abrams P. Worldwide prevalence estimates of lower urinary tract symptoms, overactive bladder, urinary incontinence and bladder outlet obstruction. BJU Int 2011;108:1132-8.

3. Cheung WW, Khan NH, Choi KK, Bluth MH, Vincent MT. Prevalence, evaluation and management of overactive bladder in primary care. BMC Fam Pract 2009;10:8.

4. Zumrutbas AE, Bozkurt AI, Tas E, Acar CI, Alkis O, Coban K, et al. Prevalence of lower urinary tract symptoms, overactive bladder and urinary incontinence in western Turkey: results of a population-based survey. Int J Urol 2014;21:1027-33.

5. Chung JH, Kim SA, Choi BY, Lee HS, Lee WS, Kim YT, et al. The association between overactive bladder and fibromyalgia syn- drome: a community survey. Neurourol Urody 2013;32:66-9.

6. Son YJ, Kwon BE. Overactive bladder is a distrees in heart failure. Int. Neurourol J 2018;22:77-82.

7. Coyne KS, Kaplan SA, Chapple CR, Sexton CC, Kopp ZS, Bush EN, et al. Rsik factors and comorbid conditions associated with lower urinary tract symptoms: EpiLUTS. BJU Int 2009;103(Suppl 3):24.

8. Coyne KS, Cash B, Kopp Z, Gelhorn H, Milsom L, Berriman S, et al. The prevalence of chronic constipations and faecal incontinence among men and women with symptoms of overactive bladder. BJU Int 2001;107:254-61.

9. Lai HH, Vetter J, Jain S, Andriole GL. Systemic non-urologic symptoms in patients with overactive bladder. J Urol 2016;196:467-72.

10. Ramos ML, Garcia-Cabo C, Leira R, Dominguez C, Pozo-Rosich P, Vila C, et al. Comorbidity between idiopathic overactive bladder and chronic migraine. Cephalalgia 2018;38:581-4.

11. Headache Classification Committee of the International Headache Society (IHS) The International Classification of Headache Disorders, 3rd edition. Cephalalgia 2018;38:1-211.

12. Acquadro C, Kopp Z, Coyne KS, Corcos J, Tubaro A, Choo MS, et al. Translating overactive bladder questionnaires in 14 languages. Urology 2006;67:536-40.

13. Tarcan T, Mangır N, Özgür MÖ, Akbal C. AOB-V8 aşırı aktif mesane sorgulama formu validasyon çalışması. Üroloji Bülteni 2012;21:113-6.

14. Breslau N, Rasmussen K. The impact of migraine. Epidemiology, risk factors and co-morbidities. Neurology 2001;56:4-12.

15. Zarifoglu M, Siva A, Hayran O. The Turkish headache epidemiology study group. An epidemiological study of headache in Turkey: a nationwide survey. Neurology 1998;50(Suppl 4):80-5.

16. Pavlovic JM, Akcali D, Bolay H, Bernstein C, Maleki N. Sex-related influences in migraine. J Neurosci Res 2017;95:587-93.

17. Gazerani P, Cairns BE. Sex-specific pharmacotherapy for migraine: a narrative review. Front Neurosci 2020;14:222.

18. Altman D, Illiadou AN, Lundholm C, Milsom I, Pedersen NL. Somatic comorbidity in women with overactive bladder syndrome. J Urol 2016;196:473-77.

19. Fowler CJ, Griffiths D, de Groat WC. The neural control of micturition. Nat Rev Neurosci 2008;9:453-66.

20. Rapp DE, Turk KW, Bales GT, Cook SP. Botulinum toxin type a inhibits calcitonin gene-related peptide from isolated rat bladder. J Urol 2006; 175:1138-42.

21. Cernuda-Morollon E, Ramon C, Martınez-Camblor P, SerranoPertierra E, Larrosa D, Pascual J. OnabotulinumtoxinA decreases interictal CGRP plasma levels in patients with chronic migraine. Pain 2015;156:820-4. 